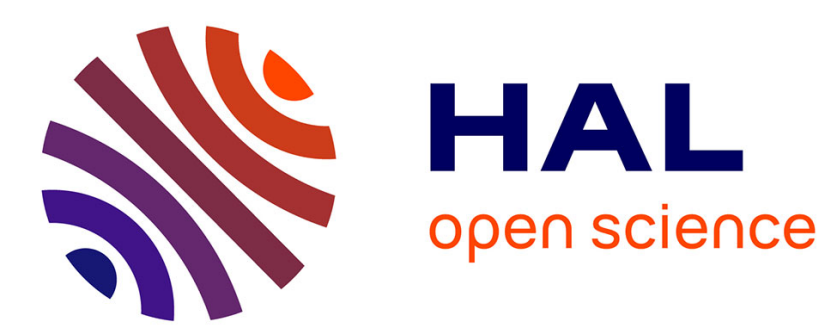

\title{
Diffuse X-ray scattering by glassy crystalline cyclohexanol: preliminary results
}

\author{
D. Ceccaldi, F. Denoyer, M. Lambert, H. Szwarc
}

\section{To cite this version:}

D. Ceccaldi, F. Denoyer, M. Lambert, H. Szwarc. Diffuse X-ray scattering by glassy crystalline cyclohexanol: preliminary results. Journal de Physique Lettres, 1980, 41 (15), pp.365-368. 10.1051/jphyslet:019800041015036500 . jpa-00231799

\section{HAL Id: jpa-00231799 https://hal.science/jpa-00231799}

Submitted on 1 Jan 1980

HAL is a multi-disciplinary open access archive for the deposit and dissemination of scientific research documents, whether they are published or not. The documents may come from teaching and research institutions in France or abroad, or from public or private research centers.
L'archive ouverte pluridisciplinaire HAL, est destinée au dépôt et à la diffusion de documents scientifiques de niveau recherche, publiés ou non, émanant des établissements d'enseignement et de recherche français ou étrangers, des laboratoires publics ou privés. 


\title{
Diffuse X-ray scattering by glassy crystalline cyclohexanol : preliminary results
}

\author{
D. Ceccaldi, F. Denoyer $\left({ }^{\dagger}\right)$, M. Lambert $\left({ }^{\dagger}\right)$ and H. Szwarc \\ Laboratoire de Chimie Physique des Matériaux Amorphes (*), Université de Paris-Sud, 91405 Orsay, France \\ $\left(^{\dagger}\right)$ Laboratoire de Physique des Solides (**), Université de Paris-Sud, 91405 Orsay, France
}

(Reçu le 8 mai 1980, accepté le 11 juin 1980)

\begin{abstract}
Résumé. - Une étude de diffusion des rayons $\mathrm{X}$ a été entreprise afin de définir des critères structuraux pour l'état cristallin vitreux. Les clichés basse température obtenus à partir de monocristaux trempés de la phase plastique du cyclohexanol révèlent une structuration des figures de diffusion que l'on peut attribuer à un désordre orientationnel où les corrélations intermoléculaires à courte distance sont fortement anisotropes. Par ailleurs, la trempe du cyclohexanol liquide a conduit à la découverte d'une phase amorphe.
\end{abstract}

Abstract. - Diffuse X-ray scattering experiments have been performed to define structural criteria for the glassy crystalline state. When quenching single crystals of the plastic phase of cyclohexanol, the low temperature photographs disclose a structuration of the diffusion patterns that can be assigned to strongly anisotropic short range intermolecular correlations within an orientational disorder. When quenching liquid samples, an amorphous cyclohexanol phase has been discovered.

In 1929 when performing heat capacity measurements on a phase obtained by cooling the high temperature crystalline modification of cyclohexanol, Kelley [1] observed a thermal phenomenon which closely looked like a glass transition; he (mis)interpreted it as a second order transition between two stable crystal phases. Analogous observations were made in other molecular crystals; Westrum and McCullough [2] systematically recorded their occurrence in the literature, assigning Type $G$ of their classification ( $\mathrm{G}$ for glass) to the corresponding transitions. They had the intuition that these transitions were somehow related to frozen-in disorder and therefore arose from quenched phases ; but it was Seki and coworkers $[3,4]$ who conclusively demonstrated that they were basically glass transitions and that such a thermal behaviour does characterize a definite species of matter aggregation obtained by quenching a phase exhibiting some kind of disorder : liquid crystals or orientationally disordered crystalline phases (such as the so-called plastic phases [5]). For the latter case, Seki coined the expression glassy crystal [3] that Cahn recently consecrated in a review paper [6]. Within these phases, the original orientational disorder

(*) Partie du L.A. 75.

(**) Laboratoire associé au C.N.R.S. is supposed to be trapped whereas the positional crystalline lattice is retained.

Because of its intricate solid phase behaviour and also because it disclosed the first historical example of a glassy crystal, cyclohexanol has been extensively studied. The higher temperature phase (or phase I) is stable between 265 and $298 \mathrm{~K}$ (see for instance [7]) and is known to be plastic according to Timmermans' criterion [5]. Indeed, NMR measurements on phase I are easily understood in terms of molecular reorientations and self-diffusion $[8,9]$. On the other hand, Corfield and Davies [10] assigned the dielectric absorption they measured to $\mathbf{H}$-bonded hydroxyl groups motions, discarding Reinisch's suggestion that it arose from chair-boat conformational changes [11]. Their assumption is substantiated by a Raman spectroscopic study showing that the ratio of axial to equatorial conformers remains constant throughout the whole phase I range [12].

$\mathrm{X}$-ray crystallographic determinations performed by Oda [13] showed that phase I is a face-centred cubic crystal $(\mathrm{Fm} 3 \mathrm{~m})$ with four molecules per unit cell. By cooling to $77 \mathrm{~K}$ (even at a moderate rate) phase I is easily supercooled to its glassy crystalline state the glass transition of which is $T_{\mathrm{g}}^{\prime}=150 \mathrm{~K}$ [3]. Otsubo and Sugawara [14] have observed similar $\mathrm{X}$-ray photographs at 285 and $83 \mathrm{~K}$, thus showing that the glassy crystalline structure (that we will call 
phase $\mathrm{I}_{G}^{\prime}$ ) also is a face-centred one. Far infrared spectroscopy has shown that phase $I_{G}^{\prime}$ contains both equatorial and axial conformers and intermolecular hydrogen bonding like all other cyclohexanol solid phases [15]. Now, the concept of frozen-in states, which seems to be underlying that of glassy crystalline state [16], implies that some inter- or intramolecular motions would cease to be observable at $T_{\mathrm{g}}^{\prime}$ and downwards. But a secondary (or $\beta$ ) dielectric dispersion domain has been observed in $\mathrm{I}_{G}^{\prime}$ [17] like in most glassy matrices [18]. Seki and coworkers have assigned it to $-\mathrm{OH}$ rotational motions [17]. Furthermore, broad-line NMR measurements show that the proportion of reorientating molecules with a frequency of $\sim 10^{5} \mathrm{~Hz}$ becomes negligible only below 100 $110 \mathrm{~K}$ [9].

So the nature of the disorder involved in a glassy crystal structure is still mysterious. For the time being, only the emergence of a glass-like transition during heat capacity measurements or the existence of longtime enthalpy relaxation, that are thermodynamic criteria, can be used to characterize the glassy crystalline state.

The purpose of the present work was to try and get a structural criterion to characterize the glassy crystalline state of cyclohexanol through diffuse X-ray scattering measurements. Our aim is to get a description of molecular orientational correlations in order to define an eventual local disorder. In this note, preliminary results are reported.

One millimeter diameter Lindemann capillaries were filled with cyclohexanol (Fluka purissimum; melting temperature $=295 \mathrm{~K}$ ) and sealed off under an argon atmosphere. Fixed single crystals, obtained by zone refining within the capillaries and subsequently orientated, were studied by X-ray monochromatic Laue technique (incident wavelength equal to $1.54 \AA$ : $\mathrm{CuK} \alpha$ ). The diffuse X-ray scattering was recorded on fixed photographic plates located some $36 \mathrm{~mm}$ from the samples. Temperature could be varied from 80 to $300 \mathrm{~K}$ thanks to a gaseous nitrogen flow.

For each studied orientation, photographs were taken at $\sim 289,273$ and $120 \mathrm{~K}$. The first two temperatures correspond to the plastic phase, the last one to the glassy crystalline state. Ten different crystal orientations have been studied in this way.

In each case, photographs of phase $I_{G}^{\prime}$ exhibited the same Bragg reflexions as phase I did, thus supporting Otsubo and Sugawara's findings [14] according to which these phases have the same lattices. Furthermore, our experiments confirm that a single cyclohexanol glassy crystal is easily obtained by cooling a single crystal of phase I. Of course, we have no information to decide whether such a feat can systematically be accomplished for any compound which leads to a glassy crystalline state.

For each orientation, the diffuse scattering intensity distinguishly drops when the temperature is lowered from 289 to $273 \mathrm{~K}$ and does not seem to decrease any more from 273 to $120 \mathrm{~K}$. From this latter result, it can be concluded that at $120 \mathrm{~K}$ the diffuse scattering is probably related to orientational disorder, whether static or dynamic, in contrast with what occurs in phase I within which the disorder is known to be a dynamic one.

Figure 1 shows two photographs recorded at 290 (Fig. 1a) and $120 \mathrm{~K}$ (Fig. 1b) respectively, with the incident X-ray beam perpendicular to plane (111). Both these photographs, corresponding to $30 \mathrm{~min}$. exposures, exhibit three (111) Bragg reflexions and three (222) ones. In fact, Bragg condition is not exactly fulfilled for the three (111) reflexions which are out of focus. What is observed corresponds to elliptical diffuse patterns accompanying (111) reflexions. It is to be stressed that such elliptical patterns were always observed near (111) reflexions but that these reflexions themselves appear as real near circular dots on precession photographs.

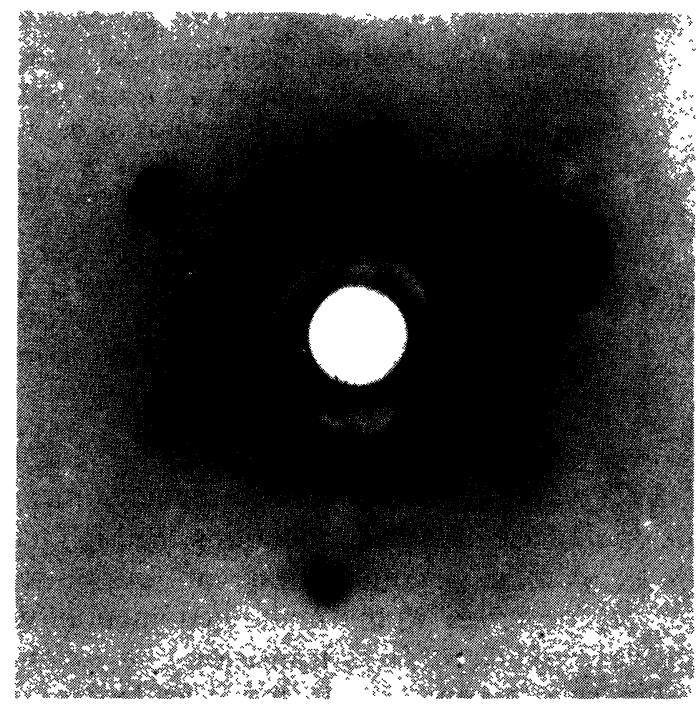

(l)

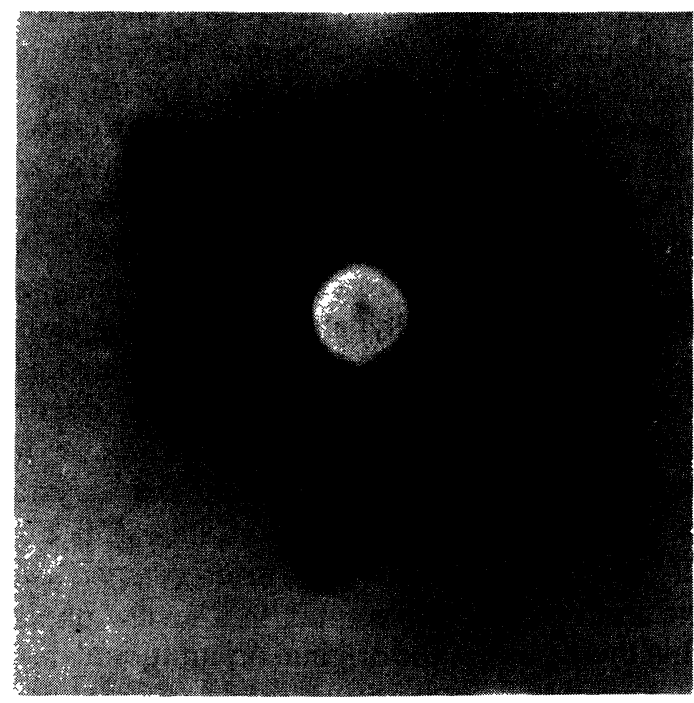

b)

Fig. 1. - Diffuse X-ray scattering by a cyclohexanol single crystal with the incident beam perpendicular to plane (111):a) Plastic phase at $290 \mathrm{~K}$; b) Glassy crystalline phase at $120 \mathrm{~K}$. 


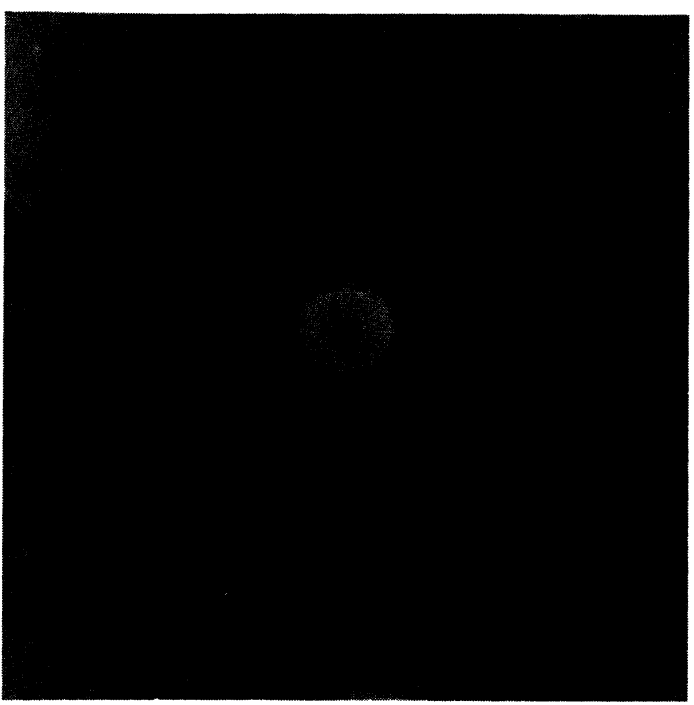

a)

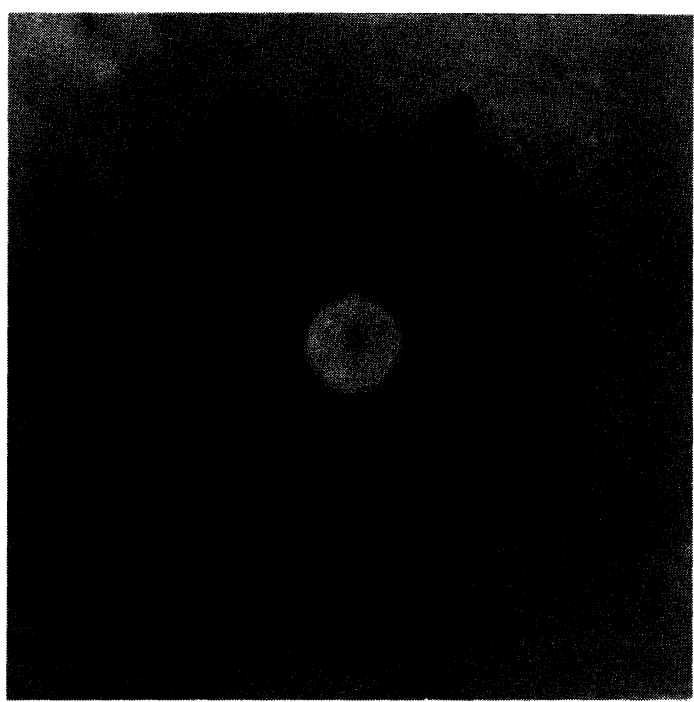

b)

Fig. 2. - Diffuse X-ray scattering by a cyclohexanol single crystal with the incident beam perpendicular to plane (100) : a) Plastic phase at $289 \mathrm{~K} ; b)$ Glassy crystalline phase at $120 \mathrm{~K}$.

In a similar way, figure 2 shows two photographs recorded at $\sim 290$ (Fig. 2a) and $120 \mathrm{~K}$ (Fig. 2b) with the beam perpendicular to plane (100). They both exhibit four (200) Bragg reflexions and eight (311) ones, which illustrates once more the similarity of phases $I$ and $I_{G}^{\prime}$.

But the more striking feature of these results lies in the structure of the diffusion patterns themselves. Whereas the inner rim of the diffusion ring is almost circular in the plastic phase at $289 \mathrm{~K}$ (and also at $273 \mathrm{~K}$ ) whatever the $\mathrm{X}$-ray beam direction is, it is no longer true at $120 \mathrm{~K}$ in phase $\mathrm{I}_{\mathrm{G}}^{\prime}$. On figure $1 b$, the former diffusion ring can be described as a truncated equilateral triangle and figure $2 b$ exhibits an almost octogonal diffusion pattern. Analogous changes were observed for any direction of the incident X-ray beam.
From these results, it can be inferred that strongly anisotropic short range intermolecular correlations characterize the orientational disorder of the glassy crystalline state of cyclohexanol.

It is to be noticed that we succeeded four times to obtain glassy samples by cooling liquid cyclohexanol. Figure $3 a$ shows the X-ray photograph recorded from the melt at $\sim 300 \mathrm{~K}$. Figure $3 b$ shows a similar photograph recorded at $120 \mathrm{~K}$ after shock cooling to $77 \mathrm{~K}\left(\mathrm{~d} T / \mathrm{d} t \sim-90 \mathrm{~K} \mathrm{~s}^{-1}\right)$ : such a photograph is characteristic of an usual amorphous state. In our knowledge, this cyclohexanol glassy state was not previously known, and we were unable to find a reproducible process to get it. In our opinion, the association of figure $3 b$ and figure $1 b$ (or $2 b$ ) represents the most dramatic illustration of the structural differences between glassy and glassy crystalline states.

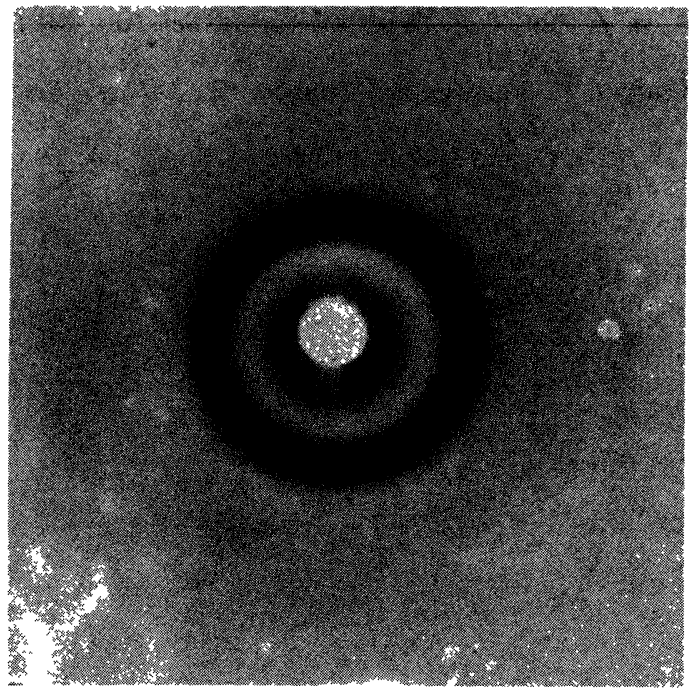

a)

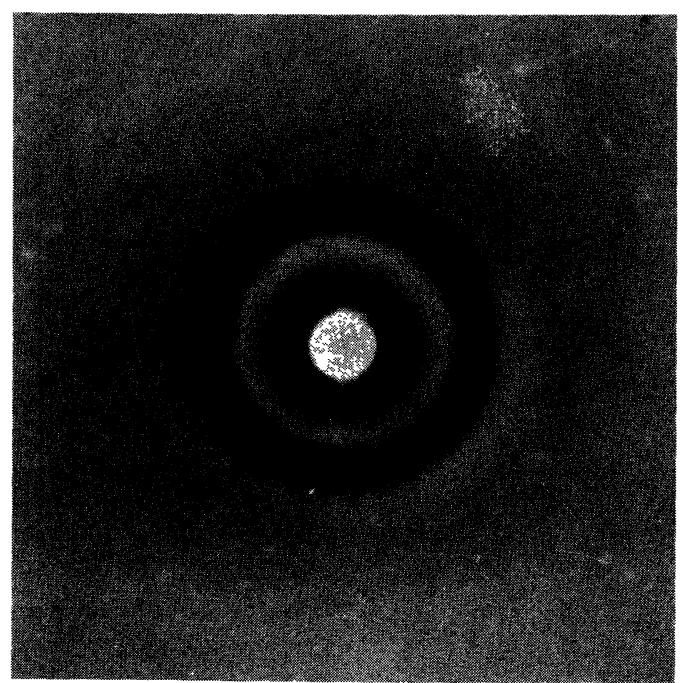

b)

Fig. 3. - Diffuse X-ray scattering by amorphous states of cyclohexanol : a) Liquid at $\sim 300 \mathrm{~K} ; b$ ) Amorphous phase obtained by quenching a liquid sample to $77 \mathrm{~K}$ : the photograph was recorded at $120 \mathrm{~K}$. 
This preliminary work has disclosed definite structural characters for cyclohexanol glassy crystal and we think that this study deserves to be carried on. To ascertain the validity of our qualitative conclusions, much computational work will be necessary to find a model of the disorder in phase $\mathrm{I}_{G}^{\prime}$ able to fit our experimental diffuse X-ray scattering results. But first, we will have to determine the molecular packing in phase I as a starting point.

\section{References}

[1] Kelley, K. K., J. Am. Chem. Soc. 51 (1929) 1400.

[2] Westrum, E. F., Jr. and McCullough, J. P., in Physics and Chemistry of the Organic Solid State, Ed. D. Fox, M. M. Labes and A. Weissberger, Vol. 1 (Interscience Publishers, New York) 1963, pp. 1-178.

[3] Adashi, K., Suga, H. and Seki, S., Bull. Chem. Soc. Japan 41 (1968) 1073.

[4] Suga, H. and Seki, S., J. Non-Cryst. Solids 16 (1974) 171.

[5] Timmermans, J., J. Chim. Phys. 35 (1938) 331.

[6] CAHN, R. W., Nature 253 (1975) 310.

[7] Green, J. R. and Griffith, W. T., Mol. Cryst. Liq. Cryst. 6 (1969) 23.

[8] Averbuch, P., C.R. Hebd. Séan. Acad. Sci. Paris 244 (1957) 3147.

[9] Eguchi, T., Soda, G. and Chihara, H., J. Magn. Reson. 23 (1975) 55.

[10] CoRfield, G. and DAVIES, M., Trans. Faraday Soc. 60 (1964) 10.
[11] Reinisch, L., J. Chim. Phys. 56 (1959) 108.

[12] James, D. W., Shurvell, H. F. and Parry, R. M., J. Raman Spectrosc. 5 (1976) 201.

[13] OdA, T., X-Ray 4 (1945) 2; ibid. 5 (1948) 26 (in Japanese).

[14] Otsubo, A. and Sugawara, T., Sci. Rep. Res. Inst. Tohoku Univ. A 7 (1955) 583.

[15] ŚCiesińsKa, E. and ŚCIesiński, J., Mol. Cryst. Liq. Cryst. 51 (1979) 9.

[16] Suga, H. and Seki, S., 69th Faraday Discussion, Paper no 20, Exeter, U. K. ; March 1980.

[17] Adachi, K., Suga, H., Seki, S., Kubota, S., Yamaguchi, S., Yano, O. and WaDA, Y., Mol. Cryst. Liq. Cryst. 18 (1972) 345.

[18] Johari, G. P. and Goldstein, M., J. Chem. Phys. 53 (1970) 2372. 